NGINEERING REPRINT SERIES

Reprint Number 35

Engineering Experiment Station

Columbia, Missouri

\title{
IRRIGATION-DRAINAGE-CLIMATOLOGY \\ (3) FOR FLAT HUMID LAND
}

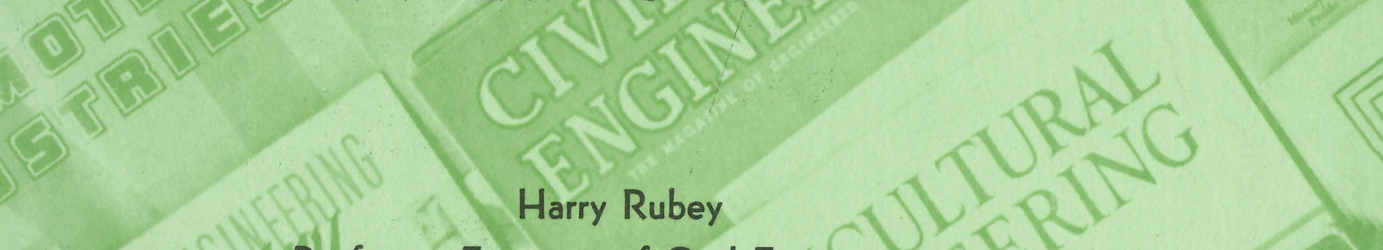

$$
\text { S } 1 \text { Professor Emeritus of Civil Engineering }
$$

Proceedings of the American Society of Civil Engineers 250 Volume 83, Paper No. 1253, May 1957 


\section{COLLEGE OF ENGINEERING \\ THE ENGINEERING EXPERIMENT STATION}

The Engineering Experiment Station was organized in 1909 as a part of the College of Engineering. The staff of the Station includes all members of the Faculty of the College of Engineering, together with Research Assistants supported by the Station Funds.

The Station is primarily an engineering research institution engaged in the investigation of fundamental engincering problems of general interest, in the improvement of engineering design, and in the development of new industrial processes.

The Station desires particularly to co-operate with industries of Missouri in the solution of such problems. For this purpose, there is available not only the special equipment belonging to the Station but all of the equipment and facilities of the College of Engineering not in immediate use for class instruction.

Inquiries regarding these matters should be addressed to

The Director, Engineering Experiment Station

University of Missouri

Columbia, Missouri

\section{THE UNIVERSITY OF MISSOURI BULLETIN}

Published by the University of Missouri at Room 102, Building T-3, Columbia, Missouri. Entered as second-class matter, January 2, 1914, at post office at Columbia, Missouri, under Act of Congress of August 24, 1912. Issued four times monthly October through May, three times monthly June through September. 
Journal of the

IRRIGATION AND DRAINAGE DIVISION

Proceedings of the American Society of Civil Engineers

IRRIGATION-DRAINAGE-CLIMATOLOGY FOR FLAT HUMID LAND1

\author{
Harry Rubey, ${ }^{2}$ M. ASCE \\ (Proc. Paper 1253)
}

\begin{abstract}
SYNOPSIS
Irrigation, drainage, and climatology are combined under professional corporate management of an engineer-agronomist-climatologist type to greatly increase profits on large holdings of flat humid lands. A pioneering development in the Mississippi River Delta is described. Phenology and operations research play important parts. Many incidental benefits will be realized.
\end{abstract}

\title{
INTRODUCTION
}

It is the purpose of this paper to describe briefly a new comprehensive program for raising living standards by permanently doubling or more the agricultural yields from flat humid lands, particularly parts of the 23,000,000 acres in the Mississippi River Delta between Cape Girardeau, Missouri and the Gulf, under professional corporate management of an engineeragronomist-climatologist type for which civil engineers are especially needed.

This will be accomplished by bringing together and synthesizing the many independent and applicable but generally unknown and specialized developments of recent years for attaining low-cost production under the most modern professional management that has been adapted to large-scale agriculture. The ground will be smoothed and sloped to perfect planes to permit ideal moisture control through surface drainage and irrigation; and bottlenecks in production, distribution, and finance will be located and removed by an "operations research" approach.

Note: Discussion open until October 1, 1957. Paper 1253 is part of the copyrighted Journal of the Irrigation and Drainage Division of the American Society of Civil Engineers, Vol. 83, No. IR1, May, 1957.

1. Presented to the American Society of Civil Engineers, February 19, 1957, at the National Spring Convention, Jackson, Mississippi, Irrigation and Drainage Section.

2. Prof. Emeritus and Chairman, Dept. of Civ. Eng., Univ. of Missouri, Columbia, Mo. 
A pioneering project will be described where this Program is under way. Initial and complete planning for new projects must be undertaken a considerable time before satisfactory results will be realized since this new culture requires study and experimentation that cannot be undertaken hurriedly or piecemeal.

With adequate promotion, Delta agriculture can quickly rival and ultimately surpass that of other regions because of its greater alluvial acreage and because cheap water for irrigation is relatively inexhaustable here as contrasted with the alarming shortage elsewhere. While the Delta can support a most intensive and profitable agriculture, it is currently producing only a fraction of that potential income and it cannot attain a generally prosperous destiny by existing methods.

Analogously, fifty years ago California was becoming unprofitable as a grain producer under dry farming, with little irrigation or industry. Since then its agriculture has revived through irrigation, has overcome great difficulties and failures that with caution can be avoided in the Delta, and has made a major contribution to the present general productivity and prosperity of that State which now leads all others in agricultural income. Profiting from California's costly experience and under modern professional management, this Program for the Delta can proceed more rapidly while avoiding the numerous pitfalls that were encountered there. An opportunity now exists here for irrigation and drainage development similar to that of the early arid West.

\section{The General Program}

With average annual rainfall of more than 50 inches and maximum rainfall of 80 inches per year, drainage has always been recognized as a primary problem for the Delta and very large main drainage systems were in operation here about World War I. A decade later the federal government began perfecting the World's best and most costly flood protection for this $23,000,000$ acres of alluvial land, more than exists throughout the rest of the United States. Although flood protection and main drainage are well advanced, surface drainage of fields has not kept pace with them. The latter "on farm" drainage under this Program will remove surplus water, prevent leaching of the soil, and facilitate early spring cultivation.

On the other hand, a minimum annual rainfall of 25 inches and poorly distributed summer rainfall in most years make irrigation mandatory here if optimum crops are to be raised.

Surface drainage and irrigation for individual fields can now be combined in one grading operation at a reasonable cost. This entire Program has only recently become possible through combining the latest advances in engineering, agronomy, climatology, phenology, professional management, and operations research; and through the availability of efficient equipment for grading, ditching, subsoiling, cultivating, and pumping.

Opportunely and historically, it is interesting to note that fifty years ago California attained part of its phenominal early growth by adopting the drainage pumps then used in New Orleans. Reciprocally, the Delta should now adopt profitable ideas from California and elsewhere. 
Moisture

Perfected control of moisture attained through surface drainage and properly scheduled irrigation (more adequately attained by using and supplementing rainfall rather than by attempting to replace it completely as in the arid West) now can keep the optimum amount of soil moisture available to the plants at the right time, not only that necessary to prevent drought damage. Hence the climate can be altered and stabilized in an optimum condition insofar as moisture is concerned and this age-old major uncertainty in crop culture prevented from further interfering with modern scientific management.

\section{Fertilizer}

The second major requirement (carefully prescribed nutrients or fertilizers provided at exactly the right time and often in the irrigation water) is on the way to solution through intensive soil testing checked by experiments and by daily quantitative observation and correction of plant growth as it occurs, all as described later in connection with Fig. 3.

\section{Other Problems}

With moisture and nutrients perfected and uniform, controlled full-size experiments become possible and other limiting factors can be better diagnosed and corrected. Also, the planting and harvesting of optimum crops can be scheduled on any desired part of the growth curve of Fig. 3, described later, much as manufactured articles are perfected and scheduled through a factory, with optimum production and with all of the attendent managerial benefits.

Of course, continuous attention under specialized advice must be given to improvement of fertilizers, strains, spacing of plants, culture, weed and pest control, defoliation, rotation, cultivation, mechanization, and the multitudinous details of good farm management. Agricultural experiment stations are continuing and expanding their research on these many details, in fact, greatly enlarged programs are being proposed to specialize in Delta problems. However, so far as known, none of these stations have developed the basic, integrated, full-size Program described later in this paper and already under way.

\section{Production Measurement and Correction}

Most of these farm management problems can be handled more effectively where optimum uniform moisture and plant nutrients are maintained, plant growth is scientifically measured and plotted daily as on Fig. 3, and deficiencies are corrected immediately as they occur.

Waiting to diagnose and perfect farm practices until harvest is as useless as an autopsy where the patient died of a combination of diseases. Furthermore, manufacturing could not prosper today without clever cost accounting. The use of Fig. 3 as referred to previously, and described later, could be called "production measurement and correction," similar in effectiveness to cost accounting.

\section{First Steps}

The first organizational step in inaugurating a new project under this 
Program is to adopt a professional corporate management approach that secures experienced advice, otherwise success will be almost impossible. Water supply and water rights are seldom a problem in the Delta.

The first physical step and the physical foundation for any successful Program where surface drainage will be helpful is to "land-form" or "level" the land to proper size, shape, and slope under specialized civil engineering direction. The broad implications of the word "proper" are known at least partly to experienced developers but inexperienced men will seriously handicap, perhaps ruin, the project through fundamental errors in these matters. Furthermore, an intimate and experienced historical knowledge of the causes of past failures is essential if their repetition is to be avoided.

Of course, sprinkling may be used where there are no drainage problems.

\section{Planning for the Future}

Along with establishment of basic surface drainage and irrigation and of reasonably satisfactory current production, professional management and operations research must study the overall policies best designed to meet the future. Although not listed in order of importance or in the order that they should be undertaken, these will include among others:

1. Diversification of crops and labor so as to approximate profitable yeararound production and employment.

2. Producing and marketing organizations as in California and Florida.

3. Consolidation of large land holdings, or a cooperative sharing of the expense of research, advice, and recruiting and training of professional management personnel.

4. Whether the organization shall continue operations as a single unit or shall split into several units under separate managers. Even more important, whether to lease or sell part of the improved large holdings to efficient operators of "family-size" units. All of these types of organization were used in older irrigated regions and will become feasible in the Delta after the land has been surface drained, irrigated, and otherwise highly improved under professional management, but not before.

It is not possible for the family-size owner or lessee to attain this advanced type of culture by himself. The original large owner must provide him with a professional management viewpoint, expert advice, financing, and rented equipment. In this way a much more prosperous and desirable community may be attained.

5. Benefits to be obtained from federal subsidies and payments.

6. Possible tax benefits.

7. Modern corporate-type financing, using both short and long-term loans.

8. The amount of acreage to be added each year.

9. Establishment of community living centers for workers and managers.

10. Adaptation to the further inevitable advances and changes that will occur.

\section{A Pioneering Project}

A description of procedure on an actual project will clarify and make definite the previous more general discussion. So far as is known, the first integration of these fundamental principles in the Delta began in the fall of 
1954 at Weona Farms, Arkansas about 45 miles northwest of Memphis, Tennessee. From among several thousand acres of cotton, a 400-acre tract was selected which had a fall of less than a foot per mile, was drained by a large ditch, and was protected under federal flood control. The ground was "leveled" or "land-formed" to perfect planes, surface drained and irrigated, and planted to cotton in the summer of 1955. Most of the work was contracted, was fairly satisfactory but expensive, and much was learned while perfecting details. Practices that had been developed in Nebraska, Iowa, California, and New Jersey were imported and adapted to local conditions. Abundant water was pumped from inexpensive wells about 100 feet deep.

\section{Organization}

The overhead organization that was built up during the first year at Weona Farms may be considered as a minimum in numbers and qualifications; it would be unsafe to proceed with less since specialization, professional management, and operations research all are involved.

The part-owner and president exercised the function of professional management from a distant Kansas City office, and his energetic and forwardlooking approach has advanced the general Delta Program many years.

Because of the recent advances made by him in theoretical and applied climatology and phenology (the relations between alterations in climate and the life and development of plants), an experienced doctor in the field of climatology was retained to advise in scheduling irrigation for optimum production, in scheduling planting and harvesting, in adapting plant physiology and culture to changed and optimum conditions, in establishing growth patterns, and the like.

A very practical doctor of agronomy was placed in charge of local operations. The writer advised regarding general policy, engineering, drainage, and irrigation. Soil specialists and others were called upon as needed.

\section{Second Year}

During 1955-56, and profiting from the experience on the first 400 -acre tract, a second 400 acres was similarly developed but in a better and less expensive manner. Marr's method of least squares was used to minimize grading and the irrigation distribution system was improved. The details at Weona Farms will be described now in connection with this second tract.

Figure 1 shows typical topography at the south end of the 400-acre contoured site, with its 100 -foot grid system of elevations.

Figure 2 shows the roadway, drainage, and irrigation systems as planned from a complete topographic map like Fig. 1 so as to give optimum size, shape and slope for each of the 23-acre to 34-acre units, each of which was graded to a perfect but different plane.

Figure 3 shows a solid-line upper curve with the vertical scale reading downward on the left to give the deficiency of available soil water under irrigation. Evaporation and transportation losses are plotted downward. Rainfall and irrigation cause the curve to rise, often to zero which means a full soil reservoir. Irrigation was applied four times in 1956 at the dates indicated by the large black dots at the top of the chart.

Without irrigation the curve follows the dotted position. 
The lower part of Fig. 3 shows the possible growth curve in this locality when there is adequate water in the root zone. Really this is the curve of accumulated transpiration with the directly proportional potential growth units reading upward on the right. Both upper and lower curves should be plotted daily.

It will be noted on the cotton curve that the actual rate of growth of the cotton began to fall below its potential rate toward the middle of July 1956. Since considerable, although perhaps not optimum, moisture had been maintained in the root zone, it is thought that the lack of quickly available fertilizer, delayed irrigation, and other matters at this critical time stunted the growth. This injury was not apparent on the plants for several weeks.

From next year's graph, when this leveling off in actual growth shows on the curve, and long before it is apparent on the plants, such remedial action as seems appropriate will be taken immediatel y by applying fertilizer in the irrigation water or otherwise, reducing weeds or pests, or whatever judgment dictates at that time.

\section{Third Year, Operations Research*}

Industry is constantly changing its operational procedures. Agriculture must do likewise and, additionally, operational change will be greatly accelerated under this Program.

Therefore next year, 1956-57, an operations research attack at Weona Farms will be concentrated on removing production bottlenecks for the existing 800 improved acres, without the distraction of planning and constructing new acreage. Through the use of this modern management tool, the long and disastrous growing pains that occurred in the arid West can be shortened and minimized. Every project will have different problems, often accentuated by the new culture.

In the second year at Weona it was noted that comprehensive study should be given in improving the important practices of weed control, fertilization, phenology, and refinement of irrigation methods. To investigate these, the management has tentatively set up, among others, the following research studies for the forthcoming season:

1. Chemical weed control using both pre-emergence and post-emergence treatments. An interesting experiment will show whether post-emergence herbicidal oils can be "floated" onto a field on top of the irrigation water.

2. Six different fertilizer treatments combining various amounts and timing of applications. These treatments will be under daily phenological observation which will give useful data on both development and the serious problem of fruit-drop, as for example the dropping of cotton squares and bales.

3. More intensive phenological observation.

4. Varying irrigation treatments ranging from "dry" to "wet." Since it is

* This latest application of research to overall management is used by the Armed Forces and industry but seldom in agriculture. See Operations Research for Management, by McClosky and Trefethan, the Johns-Hopkins Univ. Press, 1954. See also a summary in Fortune Magazine for February 1956. Both references give an agricultural example which partly explains the climatological basis for Fig. 3. 
probable that development is proportional to transpiration and further that potential evapotranspiration occurs only at field capacity, one unit will be kept at or near field capacity throughout the growing season. The "floating" method mentioned in 1 above will be tried here since the field may be too wet for application equipment.

5. More time this year (free from the construction problems accompanying the adding of new acreage) devoted to establishing future policies and objectives, looking many years ahead.

After these matters are under control, the expansion Program will be resumed.

\section{A NEW AND COMPLEX PROGRAM}

Because this new Delta Program involves the application of the latest conceptions of modern corporate professional management including operations research, organization, and the like; and recent engineering, agricultural, climatological and phenological developments - all necessarily adapted to a particular project with its own particular set of local conditions and objectives-it is obvious that both the general objectives and the varied details must be expertly established for each project separately and therefore are beyond the scope of a single paper.

Such a Program should not be undertaken except with experienced advisers and a professional management that will persevere toward optimum present and future earnings. It must be carried out completely, not partially, under specialized sympathetic personnel. Unless a project is to be wisely, comprehensively, and imaginatively approached, it would be better not to start. Common sense and common experience are not enough.

Commercial, educational, and governmental agencies work mainly with the farmer or smaller operator. The larger corporate operator, for whom this Program is suggested, therefore must secure much of his advice and service from experienced consultants who have the more applicable corporate viewpoint and plan of attack. This is the "agribusiness" or agronomics of the future, not convential farming and not apt to be successful under conventional agencies and thinking.

\section{CONCLUSIONS}

A promising and profitable new basic Program is being developed under a special type of technical and professional management. It offers stable optimum yields, low-cost production, high return on the investment, tax benefits, federal subsidy advantage, ability to diversify in using labor and by changing crops to meet changing markets and demands, and opportunity to consolidate or cooperate with other large holdings or to lease or sell parts of such improved holdings as trends in economics, politics, sociology, taxation, and personal inclination may dictate.

In brief, it will provide for both the short-range and the long-range health of the undertaking, and the benefits will go far beyond a mere doubling of crops. Early developers may profit most. Expanding agriculture will supplement fast growing industry and will correct the downward population trend existing in much of the Delta with an upgraded population.

In order to capitalize quickly and permanently its advantages of water, 
climate, soil, location, labor, and ownerships that are large enough to justify modern professional management; large-scale agriculture in the Delta must adopt such a modern Program. Each plantation can change over to the Program either slowly or more rapidly as circumstances dictate, but at least a start should be made now since the altered culture necessitates study and experimentation over some years before the best results can be realized. Only through professional management of an engineer-agronomistclimatologist type can the prosperous plantations of the Old South quickly rise again. 


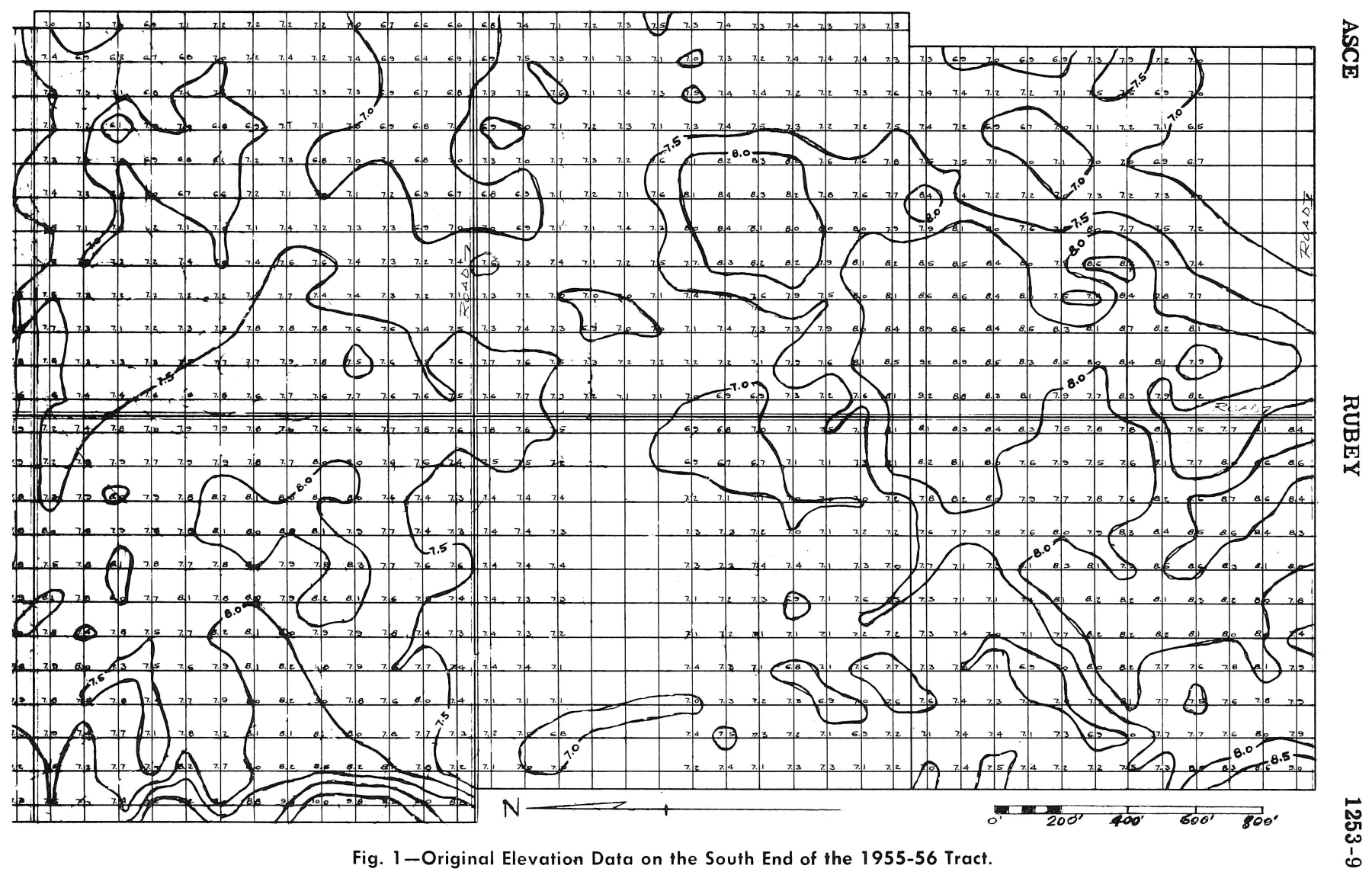




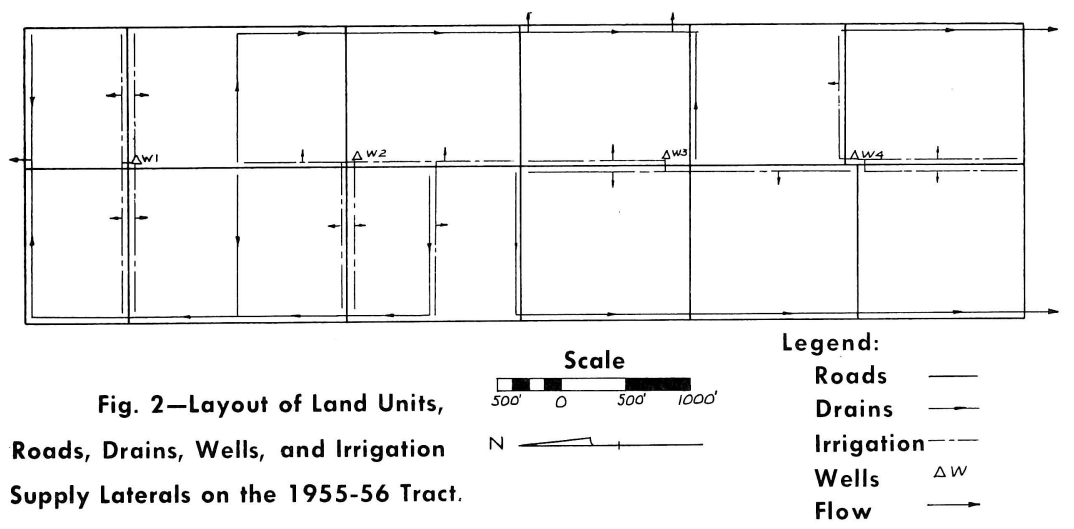

Soil

Moisture

Deficiency May

June July

August

September

Growth

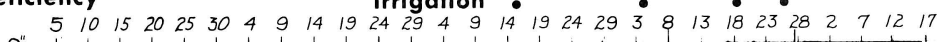

$0^{\prime \prime}$

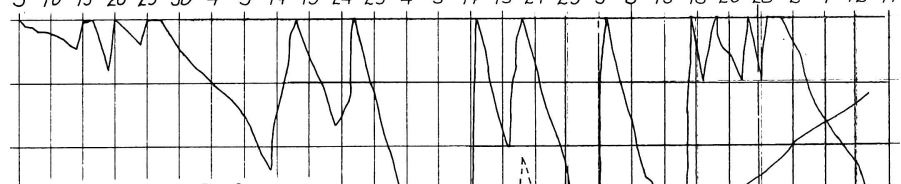

Soil Moisture Deficiency

2

(Irrigated)

3

Soil Moisture Deficiency

(Non-Irrigated)

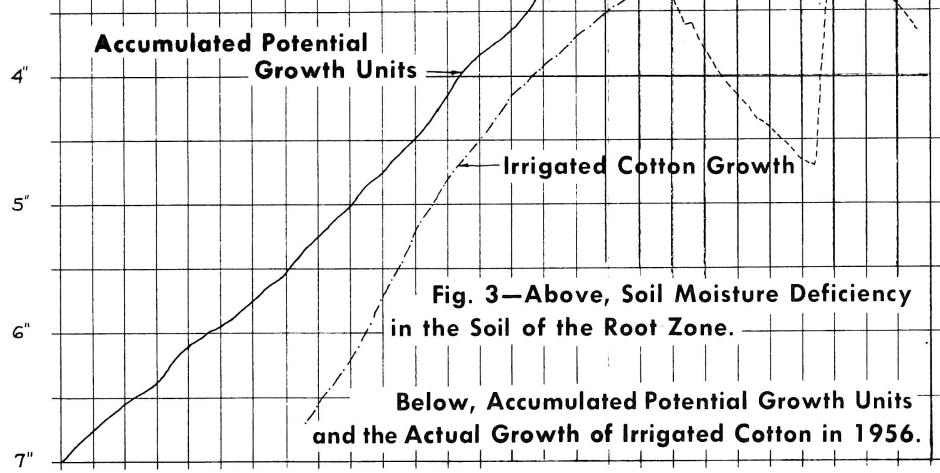






\section{PUBLICATIONS OF THE ENGINEERING REPRINT SERIES}

Copies of the complete list of publications may be secured from the Director of the Engineering Experiment Station, University of Missouri

Reprint No.

17. Additions to Sample-Data Theory by G. V. Lago, Associate Professor of Electrical Engineering. Reprinted from the Proceedings of the National Electronics Conference, Vol. 10, February 1955.

18. Additions to Z-Transformation Theory for Sample-Data Systems by Gladwyn V. Lago, Associate Professor of Electrical Engineering. Reprinted from Transactions of the American Institute of Electrical Engineers, Vol. 74, January, 1955.

19. Tension Control for High Strength Structural Bolts by Adrian Pauw, Professor of Civil Engineering and Leonard L. Howard, Lakeland Engineering Associates, Inc., with a discussion on the Turn-of-the-Nut Method by E. J. Ruble, Association of American Railroads. Reprinted from the Proceedings of the American Institute of Steel Construction, National Engineering Conference, April 18-19, 1955.

20. Autotransformer Betters Motor Phase Conversion by Joseph C. Hogan, Associate Professor of Electrical Engineering. Reprinted from Electrical World, Vol. 144, p. 120, October 17, 1955.

21. Sequence Summation Factors by Adrian Pauw, Professor of Civil Engineering. Reprinted from the Proceedings of the American Society of Civil Engineers. Vol. 81, Paper No. 763, August, 1955.

22. PulsedEddy Currents Gage Plating Thickness by Donald L. Waidelich, Associate Director, Engineering Experiment Station. Reprinted from Electronics, Vol. 28, p. 146, November, 1955.

23. Relay Protection for Lines Being Sleet-Melted by the Short-Circuit Method by J. C. Hogan, Associate Professor of Electrical Engineering and C. G. Pebler, Commonwealth Associates, Inc. Reprinted from Transactions of the American Institute of Electrical Engineers, Vol. 74, December, 1955.

24. Supplemental Irrigation....Careful Planning is Essential by Harry Rubey, Professor of Civil Engineering. Reprinted from What's New in Crops and Soils, Vol. 7, August-September, 1955.

25. Analysis of Single-Phase-to-Three-Phase Static Phase Converters by J. C. Hogan, Associate Professor of Electrical Engineering. Reprinted from Transactions of the American Institute of Electrical Engineers, Vol. 74, p. 403, January, 1956.

26. Enrollment and Incomes in Civil Engineering can be Increased by Harry Rubey, Professor of Civil Engineering. Reprinted from Journal of Engineering Education, Vol. 46, p. 236, November, 1955.

27. A Synthesis Procedure for Sampled-Data Systems by G. V. Lago, Associate Professor of Electrical Engineering. Reprinted from Proceedings of the National Electronics Conference, Vol. 11, p. $251,1955$.

28. Design of Optimum Phase-Shift Oscillators by Donald L. Waidelich, Associate Director, Engineering Experiment Station. Reprinted from Proceedings of the National Electronics Conference, Vol. 11, p. 222, 1955. This article also appeared in Electronics Equipment, Vol. 4, p. 38, April, 1956.

29. Investigation Concerning Polarization in Barium Titanate Ceramics by G. W. Marks, U. S. Navy Electronics Laboratory, Donald L. Waidelich, Associate Director Engineering Experiment Station, University of Missouri and L. A. Monson, U. S. Navy Electronics Laboratory. Reprinted from Transactions of the American Institute of Electrical Engineers, Vol. 75, Part I, p 469, 1956.

30. The Influence of Shank Area on the Tensile Impact Strength of Bolts by John Love, Jr., General Electric Company and O. A. Pringle, Associate Professor of Mechanical Engineering. Reprinted from Transactions of the American Society of Mechanical Engineers, Vol. 78, p 1489, October, 1956.

31. Measurement of Coating Thicknesses by Use of Pulsed Eddy Currents by Donald L. Waidelich, Associate Director, Engineering Experiment Station. Reprinted from Nondestructive Testing, Vol. 14, p 14, MayJune 1956.

32. Head Losses in Storm Drain Junction Boxes by Horace W. Wood, Professor of Civil Engineering. Reprinted from Highway Research Board Proceedings, Vol. 35, p 177, 1956.

33. Stability of Laminar Flow in Curved Channels by Chia-Shun Yih, Associate Professor of Engineering Mechanics, University of Michigan and W. M. Sangster, Associate Professor of Civil Engineering, University of Missouri. Reprinted from The Philosophical Magazine, Volume 2, Eighth Series, Page 305, March 1957.

34. Viscosity of Suspensions of Spherical and Other Isodimensional Particles in Liquids by Andrew Pusheng Ting, Chemical Construction Corporation and Ralph H. Luebbers, Professor of Chemical Engineering, University of Missouri. Reprinted from the American Institute of Chemical Engineers Journal, Volume 3, Page 111, March, 1957.

35. Irrigation-Drainage-Climatology for Flat Humid Land by Harry Rubey, Professor Emeritus of Civil Engineering. Reprinted from the Proceedings of the American Society of Civil Engineers, Volume 83, Paper No. 1253, May 1957.

*Out of Print. 

University of Missouri Libraries

University of Missouri

MU Engineering Experiment Station Series

Local Identifier

Rubey1957

Capture information
Date captured
2018 May
Scanner manufacturer Ricoh
Scanner model
MP C4503
Scanning software
Optical resolution
600 dpi
Color settings
File types
Grayscale, 8 bit; Color, 24 bit
Tiff

Source information

Format

Content type

Notes
Book

Text

Digitized duplicate copy not retained in collection.

Derivatives - Access copy

Compression

Editing software

Resolution

Color

File types

Notes

\section{LZW}

Adobe Photoshop

$600 \mathrm{dpi}$

Grayscale, 8 bit; Color, 24 bit

Tiffs converted to pdf

Greyscale pages cropped and canvassed. Noise removed from background and text darkened. Color pages cropped. 